\title{
The development of self-efficacy and outcome expectation measures regarding glycaemic load and the nutritional management of type 2 diabetes
}

\author{
Carla K Miller ${ }^{1}$, Melissa Davis Gutschall ${ }^{2}$ and Frank Lawrence ${ }^{3}$ \\ ${ }^{1}$ Penn State Diabetes Center, Pennsylvania State University, 113 Noll, University Park, PA 16802, USA: ${ }^{2}$ Department \\ of Nutritional Sciences, Pennsylvania State University, 5 Henderson Building, University Park, PA 16802, USA: \\ ${ }^{3}$ Department of Human Development \& Family Studies, Pennsylvania State University, S-163 Henderson Building, \\ University Park, PA 16802, USA
}

Submitted 13 December 2005: Accepted 24 May 2006: First published online 5 March 2007

\begin{abstract}
Objective: Traditionally, carbohydrate has been the largest contributor to energy intake among people with diabetes, yet different carbohydrate foods produce different glycaemic responses. Glycaemic load represents the total glycaemic effect of the diet and influences glycaemic control. Adequate self-efficacy and outcome expectations are needed to change carbohydrate intake and to evaluate relevant interventions. The purpose of this research was to develop and test instruments regarding self-efficacy and outcome expectations for the adoption of a lower glycaemic load diet.

Design: Participants completed each instrument at their convenience and mailed the instruments to the investigators.

Setting/subjects: A community sample of individuals $21-75$ years of age with type 2 diabetes for $\geq 1$ year $(n=108$ ) was recruited.

Results: Principal components analysis revealed three factors on the self-efficacy questionnaire: glycaemic index, negative food selection and self-regulation efficacy which accounted for $62 \%$ of the variance in these items. The outcome expectations instrument yielded three factors: barriers to dietary change and glycaemic control, and family support expectations which accounted for $48 \%$ of the variance. Coefficient $\alpha$ for each construct was $>0.70$ and coefficient $H$ for each construct was $\geq 0.80$.

Conclusions: The two instruments developed for this study can provide important insights about the self-efficacy and outcome expectations regarding the quantity and quality of carbohydrate consumed and self-monitoring performed for diabetes management. Future research is needed to evaluate the relationship among these constructs, dietary intake and glycaemic control.
\end{abstract}

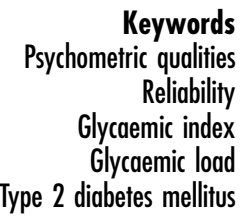

Diabetes mellitus is a leading cause of morbidity and mortality in the USA ${ }^{1}$. The prevalence of diabetes in the US population increased 49\% from 1990 to $2000^{2}$, and the global prevalence of diabetes is projected to double between 2000 and $2030^{3}$. Recent clinical trials demonstrate that nutrition is an essential component of successful diabetes management ${ }^{4,5}$. Food selection determines the nutrient and energy content of the diet and affects the metabolic control and risk for co-morbidities associated with diabetes ${ }^{6}$.

Dietary recommendations for people with diabetes recommend carbohydrate as the largest contributor to total energy intake, but different carbohydrate foods produce different glycaemic responses ${ }^{6-8}$. The glycaemic response to various carbohydrate-containing foods is related to differences in the rate at which the carbohydrate is digested and absorbed. The glycaemic index (GI) was introduced as a means of ranking carbohydrate-containing foods according to their glycaemic effect, and represents the quality of carbohydrate consumed ${ }^{9}$. Glycaemic load (the product of the GI of individual foods and their carbohydrate content) characterises the impact of foods or dietary patterns with different macronutrient composition on glycaemic response and takes into account the quality and quantity of carbohydrate consumed ${ }^{10}$. A low glycaemic load (GL) diet has been linked to decreased risk for type 2 diabetes $^{11-13}$ and colorectal cancer ${ }^{14,15}$. Similarly, a lower GI diet has been associated with a lower body mass index ${ }^{16}$ and improved insulin sensitivity ${ }^{17}$, glycaemic control ${ }^{18-21}$ and fasting serum lipids ${ }^{17,22,23}$. A recent meta-analysis of the effect of lower GI diets in the management of diabetes provided evidence that lower GI diets improve glycaemic control beyond that obtained by high GI diets ${ }^{24}$. 
Effective diabetes management frequently requires the adoption of new behaviours. Social cognitive theory (SCT) has been widely used in health-related research and in diabetes programmes to explain the behaviour change process. Specifically, SCT has been used to develop diabetes prevention interventions ${ }^{25}$, to evaluate the self-care practices of people with diabetes ${ }^{26,27}$, to assess adherence to diabetes regimens ${ }^{28}$ and to implement diabetes education programmes $^{29}$. SCT postulates that behaviour is influenced by the constant interaction among the environment, the personal characteristics of an individual (e.g. outcome expectations, self-efficacy and behavioural capability), the behaviour and results of that behaviour (which can be identified through self-monitoring) ${ }^{30}$. An outcome expectation is the expected result of a behaviour ${ }^{31}$. The more positive the result is perceived to be the more likely it is that the person will engage in the behaviour. Self-efficacy is how confident a person feels about performing a specific behaviour in a particular circumstance ${ }^{31}$. Those with greater degrees of self-efficacy are more likely to engage in the behaviour and persist in the face of obstacles. Selfmonitoring provides feedback regarding the effectiveness of the behaviour. According to SCT, people must be exposed to the behavioural goal. Then, outcome expectations provide the motivation for changing behaviour, knowledge ensures the person knows what behaviour to perform, selfefficacy provides the confidence for overcoming obstacles and self-monitoring provides relevant feedback.

Instruments to assess an individual's outcome expectations and self-efficacy regarding carbohydrate intake, self-monitoring blood glucose and diabetes management have not been reported in the literature. As more emphasis is placed on the quantity and quality of carbohydrate consumed (i.e. GL) by people with diabetes to achieve and maintain optimal glycaemic control, valid and reliable instruments are needed to evaluate educational efforts adequately. Therefore, the purpose of this research was to evaluate the psychometric qualities of two instruments designed to assess outcome expectations and self-efficacy regarding carbohydrate intake and self-monitoring for diabetes management.

\section{Methods}

\section{Instruments}

Two instruments were developed to address self-efficacy and outcome expectations regarding the quantity and quality of carbohydrate intake (i.e. GL) and self-monitoring blood glucose. Items were selected for each instrument that represented the range of beliefs and skills needed to adopt a lower GL diet identified from clinical practice and previous research ${ }^{29,32,33}$. For example, the self-efficacy instrument included 20 questions, with 10 of the questions designed to measure confidence in using the GI to make healthy food choices. The remaining questions assessed confidence to control portion sizes of food, carbohydrate intake and self-monitoring for optimal glycaemic control.
Confidence to control both the quantity of food consumed through controlled portion sizes plus confidence to select lower GI foods is one method for achieving a lower GL diet. Response options ranged from $0=$ strongly disagree to $10=$ strongly agree. Instruments with fewer response options (e.g. 5- or 7-point scales) are less desirable because they are less sensitive ${ }^{34,35}$. Thus, response options ranged from 0 to 10 for both instruments in this study. Both positively and negatively stated behaviours were included on the instrument. The negatively stated items were reverse scored so that 'strongly disagree' received a score of 10 .

The outcome expectations instrument included 18 questions designed to measure participants' strength of belief in the relationship among dietary intake, selfmonitoring blood glucose, glycaemic control and health. The response options ranged from $0=$ strongly disagree to $10=$ strongly agree. Once again, both positively and negatively stated expectations were included on the instrument. The negative expectations (i.e. barrier statements) were reverse scored so that 'strongly disagree' received a score of 10 . For both instruments, the mean score for each construct was obtained by totalling the points and dividing by the number of items comprising each construct to indicate the strength of beliefs or perceived efficacy for each latent construct ${ }^{34}$.

\section{Assessment of content validity}

Content validity exists when an instrument provides systematic coverage of the domain of tasks the instrument is designed to measure ${ }^{36}$. An objective evaluation by content specialists of the depth, breadth and relevance of the items to the content domain is conducted to measure content validity ${ }^{37}$. Four dietitians and one nurse with multiple years of experience in diabetes education reviewed both instruments for content validity. Reviewers received a brief description of the purpose of the intervention and target audience for whom the instruments were developed, the objectives of each instrument, the items on each instrument and the objective each item was designed to measure. Each reviewer rated the degree to which each item measured its intended objective using a 4 -point scale $(1=$ not relevant to $4=$ very relevant $)$ and the degree to which the instrument as a whole measured the content domain using the same 4-point scale. Reviewers were also asked to list areas in the nutritional management of diabetes that were omitted and should be included on the instrument and suggestions for improving each instrument. Reviewers completed their review independently and did not have access to each others' comments or ratings.

\section{Pilot testing of the instruments}

Adults 21-75 years of age diagnosed with type 2 diabetes mellitus for $\geq 1$ year were recruited over a 6-month period to pilot test the instruments. Subjects were recruited through newspaper advertisements, flyers, diabetes support group meetings, physicians' offices and referral from 
other participants. All interested subjects were screened for study eligibility through a telephone screening interview. All interested and eligible subjects were mailed the instruments to complete at home with a self-addressed, stamped envelope for return to the investigators upon completion. Individuals reported completing both instruments in $\sim 15 \mathrm{~min}$. Participants provided written informed consent and received a small monetary honorarium upon study completion. All methods were approved by the institutional review board at the sponsoring institution.

\section{Data analyses}

Principal components analysis with promax rotation was conducted on data obtained from the administration of the self-efficacy and outcome expectations questionnaires to study participants with diabetes. The number of factors retained was determined based on examination of the scree plot and interpretability of resulting factors ${ }^{38,39}$. Factors with eigenvalues $>1.6$ and items with loadings $>0.45$ were retained. Coefficient $\alpha$ was calculated for each construct to assess internal consistency. Coefficient $H$ was calculated to assess the reliability for each construct based on the factor loadings obtained ${ }^{40}$. The degree of association among constructs from the outcome expectations questionnaire with constructs from the self-efficacy questionnaire was determined using Pearson correlations. Analysis was conducted using SAS (version 9.1, 2003; SAS Institute).

\section{Results}

\section{Results of content validity}

The index of content validity is determined by calculating the proportion of items given a rating of 3 or 4 by all reviewers ${ }^{36}$. Scores can range from 0.0 to 1.0. The index of content validity for the self-efficacy instrument and outcome expectations instrument was 0.70 and 0.50 , respectively. The index of content validity for the outcome expectations instrument was below the recommended index of $0.70^{41}$. Based on reviewer comments on the items with low relevance ratings on the outcome expectations instrument, three items were modified to be more specific in the outcome described. Two items were deleted since the reviewers believed the questions were ambiguous. Three new items about the degree to which family members would support participants' efforts to eat a healthier diet and monitor their blood glucose were added based on reviewers' recommendations. The final outcome expectations instrument included 19 items. No changes were made to the selfefficacy instrument. The revised version of the instruments was not reviewed again for content validity since minimal changes were made to the items. The revised instruments were mailed to study participants as described above.

\section{Results of pilot testing}

One hundred and thirty-seven people with type 2 diabetes responded to recruitment notices and received the instruments for completion. One hundred and eight (79\%) returned completed questionnaires. Over half of the sample (57.4\%) was male, $92.3 \%$ were white and $64.5 \%$ were married. The mean ( \pm standard deviation, SD) age of the sample was $55.8( \pm 9.2)$ years and they had been diagnosed with diabetes for a mean $( \pm S D)$ of $6.3( \pm 6.3)$ years (Table 1). The majority (95.4\%) of participants reported monitoring their blood glucose at home, and $73.3 \%$ reported receiving instruction to follow a meal plan or diet for diabetes management.

The outcome expectations questionnaire yielded three factors: barriers to dietary change, glycaemic control expectations and family support expectations (Table 2). These three constructs accounted for $48 \%$ of the variance in these items. Four items did not load on any of the factor scales. All of the coefficient $\alpha$ values for internal consistency were $\geq 0.78$. Reliabilities based on coefficient $H$ were $\geq 0.85$ for each of the constructs.

The self-efficacy instrument yielded three factors: GI efficacy, negative food selection efficacy and selfregulation efficacy (Table 3). These three constructs accounted for $62 \%$ of the variance in these items. Three items did not load on a single factor scale. All of the coefficient $\alpha$ values for internal consistence were $\geq 0.77$.

Table 1 Characteristics of study participants $(n=108)$

\begin{tabular}{|c|c|c|}
\hline Characteristic & Mean & SD \\
\hline Age (years) & 55.8 & 9.2 \\
\hline Age at diagnosis of diabetes (years) & 49.4 & 9.3 \\
\hline Duration of diabetes (years) & 6.3 & 6.3 \\
\hline Body mass index $\left(\mathrm{kg} \mathrm{m}^{-2}\right)^{\star}$ & 33.1 & 9.7 \\
\hline No. of days per week monitor blood glucose & 5.1 & 2.3 \\
\hline \multirow[t]{2}{*}{ No. of times per day monitor blood glucose } & 1.9 & 1.2 \\
\hline & $n$ & $\%$ \\
\hline \multicolumn{3}{|l|}{ Educationt } \\
\hline$<12$ th grade & 3 & 2.8 \\
\hline High school degree & 39 & 36.8 \\
\hline Some college/trade school & 21 & 19.8 \\
\hline College graduate or advanced degree & 43 & 40.6 \\
\hline \multicolumn{3}{|l|}{ Employment† } \\
\hline Full-time $\left(\geq 32 \mathrm{~h}\right.$ week $\left.^{-1}\right)$ & 57 & 54.3 \\
\hline Part-time $\left(<32 \mathrm{~h} \mathrm{week}^{-1}\right)$ & 8 & 7.6 \\
\hline Retired/full-time homemaker/student & 33 & 31.4 \\
\hline Disabled & 7 & 6.7 \\
\hline \multicolumn{3}{|l|}{ Self-assessment of health statust } \\
\hline Excellent & 3 & 2.8 \\
\hline Very good or good & 73 & 67.6 \\
\hline Fair or poor & 32 & 29.6 \\
\hline \multicolumn{3}{|l|}{ Diabetes management† } \\
\hline Self-monitor blood glucose at home & 103 & 95.4 \\
\hline Record blood glucose readings & 84 & 80.8 \\
\hline Adjust food intake based on glucose values & 76 & 71.0 \\
\hline Instructed to follow a meal plan or diet & 77 & 73.3 \\
\hline Instructed to follow a low glycaemic index diet & 9 & 8.3 \\
\hline \multicolumn{3}{|l|}{ Annual household incomet } \\
\hline$<$ US\$20 000 & 19 & 18.6 \\
\hline US\$20000-US\$39999 & 27 & 26.5 \\
\hline US $\$ 40000-$ US $\$ 59999$ & 28 & 27.5 \\
\hline$\geq$ US $\$ 60000$ & 28 & 27.5 \\
\hline
\end{tabular}

SD - standard deviation.

${ }^{*}$ Based on self-reported measures of height and weight.

† Some items do not equal $100 \%$ due to missing data. 
Table 2 Factor structure for the outcome expectations questionnaire

\begin{tabular}{|c|c|c|c|}
\hline Item* & $\begin{array}{l}\text { Factor } 1 \\
\text { loadings }\end{array}$ & $\begin{array}{l}\text { Factor } 2 \\
\text { loadings }\end{array}$ & $\begin{array}{l}\text { Factor } 3 \\
\text { loadings }\end{array}$ \\
\hline \multicolumn{4}{|l|}{ Factor 1: barriers to dietary change } \\
\hline It is too difficult for me to substitute low glycaemic index foods into my meal plan. & 0.75 & 0.06 & 0.12 \\
\hline It takes too much time to measure the portions of food I eat. & 0.74 & -0.03 & -0.00 \\
\hline It is too difficult to count the grams of carbohydrate of the foods I eat. & 0.71 & -0.02 & -0.03 \\
\hline It takes too much time to plan a healthy diet. & 0.71 & -0.19 & 0.03 \\
\hline If I eat a healthy diet, I will not be able to eat the foods I like when I eat out. & 0.54 & -0.06 & -0.06 \\
\hline If I eat a healthy diet, I will have to prepare more foods from 'scratch'. & 0.54 & 0.12 & -0.07 \\
\hline If I eat a healthy diet, I will be limited in the foods I can buy at the supermarket. & 0.51 & 0.10 & -0.05 \\
\hline \multicolumn{4}{|l|}{ Factor 2: glycaemic control expectations } \\
\hline $\begin{array}{l}\text { If I control my blood glucose, I will reduce my chances of developing } \\
\text { heart, eye and kidney disease and risk for amputation. }\end{array}$ & -0.08 & 0.83 & 0.06 \\
\hline The serving size of the foods I eat affects my blood glucose after a meal. & -0.10 & 0.79 & -0.04 \\
\hline If I follow my meal plan, I will have better control of my blood glucose. & 0.18 & 0.70 & -0.04 \\
\hline If I count the grams of carbohydrate I eat, I will have better control of my blood glucose. & 0.04 & 0.66 & 0.15 \\
\hline If I make low glycaemic index food substitutions, I will have better control of my blood glucose. & 0.16 & 0.54 & 0.12 \\
\hline \multicolumn{4}{|l|}{ Factor 3: family support expectations } \\
\hline My family will support my efforts to eat a healthier diet. & 0.09 & -0.08 & 0.95 \\
\hline My family will support my efforts to monitor my blood glucose. & 0.02 & 0.00 & 0.95 \\
\hline My family will feel better about my health if my blood glucose is well controlled. & -0.19 & 0.17 & 0.85 \\
\hline Eigenvalue & 4.34 & 2.89 & 1.89 \\
\hline$\%$ variance explained & $23 \%$ & $15 \%$ & $10 \%$ \\
\hline Coefficient $\alpha$ & 0.80 & 0.78 & 0.92 \\
\hline Coefficient $H$ & 0.85 & 0.86 & 0.96 \\
\hline Mean (SD)† & $5.29(2.1)$ & $8.51(1.5)$ & $8.10(2.5)$ \\
\hline \multicolumn{4}{|l|}{ Items not loading on any factor } \\
\hline It is too painful to monitor my blood glucose every day. & 0.40 & 0.21 & -0.00 \\
\hline It takes too much time to monitor my blood glucose every day. & 0.34 & 0.26 & 0.03 \\
\hline I will have better control of my blood glucose if I monitor my glucose at home. & 0.31 & 0.23 & 0.01 \\
\hline It is too expensive to monitor my blood glucose every day. & 0.26 & 0.17 & -0.22 \\
\hline
\end{tabular}

SD - standard deviation.

${ }^{*}$ Response options ranged from $0=$ strongly disagree to $10=$ strongly agree

†The mean score for each construct was obtained by totalling the points and dividing by the number of items comprising each construct to indicate the strength of beliefs for each latent construct.

Reliabilities were acceptable $(\geq 0.80)$ for each of the constructs based on coefficient $H$.

The strength of the relationship among constructs from the outcome expectations questionnaire and constructs from the self-efficacy questionnaire are shown in Table 4. Self-regulation efficacy was significantly related to each of the constructs comprising the outcome expectations questionnaire. The bivariate correlation between food selection efficacy and barriers to dietary change was 0.44 $(P<0.001)$. The correlation between GI efficacy and glycaemic control expectations was $0.29(P<0.01)$.

\section{Discussion}

This study is one of the first reported in the literature concerned with the identification of distinct constructs regarding carbohydrate intake and self-monitoring for diabetes management. Both the quantity and quality of carbohydrate consumed affect glycaemic control, and monitoring the postprandial response can assist individuals in adjusting food intake, energy expenditure and/or pharmacological therapy. Both the positive aspects of controlling food intake and self-monitoring and the barriers to performing these behaviours are captured in the instruments. The review of the items on each instrument by health care professionals with expertise in diabetes care and education enabled us to address the appropriate content domain. Furthermore, the internal consistencies of the constructs were high. This provides some support that each construct is homogeneous and can be used to assess individuals' beliefs and skills.

Coefficient $H$ is a measure of the relationship between a construct and its indicators ${ }^{40}$. It represents the proportion of variance shared by the latent construct and the observed variables and represents a measure of construct reliability. Coefficient $H$ is never less than its best indicator's reliability ${ }^{42}$. As the number of indicators increases, so does coefficient $H$, and the value of the coefficient ranges from 0 to 1.0. All of the values for coefficient $H$ for both the outcome expectations and self-efficacy constructs were $\geq 0.8$, indicating a relatively high degree of construct reliability ${ }^{42}$. A greater degree of construct reliability infers greater certainty in the magnitude of relationships observed among constructs in a given sample.

The constructs identified from the outcome expectations instrument are consistent with domains of diabetes selfcare and reflect conceptually coherent clusters of beliefs. Outcomes arise from an action. How a person behaves determines the outcomes one experiences. Positive expectations serve as incentives while negative 
Table 3 Factor structure for the self-efficacy questionnaire

\begin{tabular}{|c|c|c|c|}
\hline Item* & $\begin{array}{l}\text { Factor } 1 \\
\text { loadings }\end{array}$ & $\begin{array}{l}\text { Factor } 2 \\
\text { loadings }\end{array}$ & $\begin{array}{l}\text { Factor } 3 \\
\text { loadings }\end{array}$ \\
\hline \multicolumn{4}{|l|}{ Factor 1: glycaemic index efficacy } \\
\hline I can prepare recipes using foods with a low glycaemic index. & 0.88 & -0.02 & -0.06 \\
\hline I can prepare foods in ways that lower the glycaemic index value. & 0.88 & -0.02 & 0.04 \\
\hline I can select low glycaemic index foods at the supermarket. & 0.87 & 0.02 & 0.05 \\
\hline I can make healthy food choices based on the glycaemic index value of foods. & 0.79 & -0.10 & 0.07 \\
\hline I can choose low glycaemic index foods when I eat out. & 0.75 & 0.05 & 0.17 \\
\hline $\begin{array}{l}\text { I can use carbohydrate counting and glycaemic index guidelines together when } \\
\text { planning my meals. }\end{array}$ & 0.60 & 0.00 & 0.29 \\
\hline $\begin{array}{l}\text { I can substitute one low glycaemic index food for one high glycaemic index food } \\
\text { at each meal. }\end{array}$ & 0.58 & 0.26 & 0.03 \\
\hline \multicolumn{4}{|l|}{ Factor 2: negative food selection efficacy } \\
\hline I cannot find healthy foods that fit my personal meal plan. & -0.16 & 0.80 & 0.17 \\
\hline I cannot apply the grams of total carbohydrate on the food label to my food selection. & -0.10 & 0.76 & 0.30 \\
\hline I cannot lower the glycaemic index of my diet. & 0.26 & 0.75 & -0.29 \\
\hline I cannot use the food label to determine the serving size of foods I eat. & -0.07 & 0.73 & 0.05 \\
\hline I have to make too many changes in the way I eat to follow a low glycaemic index diet. & 0.32 & 0.68 & -0.19 \\
\hline \multicolumn{4}{|l|}{ Factor 3: self-regulation efficacy } \\
\hline I can adjust my carbohydrate intake based on my blood glucose (blood sugar). & 0.17 & -0.13 & 0.78 \\
\hline I can control the amount of food I eat by measuring my portions of food. & 0.21 & -0.16 & 0.70 \\
\hline $\begin{array}{l}\text { I can make healthy food choices by reading the amount of total carbohydrate on the } \\
\text { food label. }\end{array}$ & 0.09 & 0.10 & 0.65 \\
\hline I cannot control my glucose level by monitoring my blood glucose. & -0.13 & 0.41 & 0.52 \\
\hline I can control the amount of carbohydrate I eat each day. & 0.07 & 0.29 & 0.51 \\
\hline Eigenvalue & 6.20 & 2.75 & 1.63 \\
\hline$\%$ variance explained & $36 \%$ & $16 \%$ & $10 \%$ \\
\hline Coefficient $\alpha$ & 0.92 & 0.80 & 0.77 \\
\hline Coefficient $H$ & 0.93 & 0.87 & 0.80 \\
\hline Mean (SD)† & $5.68(2.5)$ & $5.68(2.0)$ & $6.42(1.4)$ \\
\hline \multicolumn{4}{|l|}{ Items not loading on a single factor } \\
\hline I can regularly monitor my blood glucose at home. & 0.00 & 0.37 & 0.32 \\
\hline I cannot prepare foods that are low in glycaemic index. & 0.35 & 0.52 & -0.46 \\
\hline I cannot control my blood glucose levels by making changes in the foods I eat. & -0.20 & 0.43 & 0.56 \\
\hline
\end{tabular}

SD - standard deviation.

${ }^{*}$ Response options ranged from $0=$ strongly disagree to $10=$ strongly agree.

†The mean score for each construct was obtained by totalling the points and dividing by the number of items comprising each construct to indicate the strength of perceived efficacy for each latent construct.

expectations serve as deterrents. Bandura describes three types of expectations: physical, social and self-evaluative effects $^{34}$. In this study, the physical effects are captured in the outcome expectations instrument in the glycaemic control expectations (e.g. If I follow my meal plan, I will have better control of my blood glucose). The social effects are represented in the family support expectations (e.g. My family will support my efforts to eat a healthier diet). The self-evaluative effects are represented by some of the barriers to dietary change (e.g. It is too difficult to count the grams of carbohydrate of the foods I eat). Thus, the outcome expectations instrument captures both potentially positive and negative effects of making dietary changes and monitoring the results obtained. Whether the anticipated outcomes are motivating depends on the value a person places on the outcomes. A highly valued outcome (e.g. optimal glycaemic control) can be highly motivating.

Four items from the outcome expectations questionnaire regarding self-monitoring blood glucose did not load on any factor. Three of the items represented barriers to

Table 4 Pearson correlations among constructs from the outcome expectations and self-efficacy questionnairest

\begin{tabular}{lccc}
\hline & \multicolumn{3}{c}{ Self-efficacy constructs } \\
\cline { 2 - 4 } $\begin{array}{l}\text { Outcome expectation } \\
\text { constructs }\end{array}$ & $\begin{array}{c}\text { Glycaemic } \\
\text { index efficacy }\end{array}$ & $\begin{array}{c}\text { Food selection } \\
\text { efficacy }\end{array}$ & $\begin{array}{c}\text { Self-regulation } \\
\text { efficacy }\end{array}$ \\
\hline Barriers to dietary change & 0.19 & $0.44^{\star \star \star}$ & $0.29^{\star \star}$ \\
Glycaemic control expectations & $0.29^{\star \star}$ & 0.14 & $0.23^{\star}$ \\
Family support expectations & 0.18 & 0.09 & $0.32^{\star \star \star}$ \\
\hline
\end{tabular}

† Response options ranged from $0=$ strongly disagree to $10=$ strongly agree.

$\ddagger$ Items comprising these constructs were reversed scored so that $0=$ strongly agree and $10=$ strongly disagree.

${ }^{\star} P<0.05 ;{ }^{\star \star} P<0.01 ;{ }^{\star \star \star} P<0.001$ 
self-monitoring (i.e. the time, expense and pain associated with monitoring). Over $95 \%$ of the sample reported monitoring at home and reported monitoring blood glucose values a mean of 1.9 times day $^{-1}$ (data not shown). Thus, most participants performed the behaviour but did not monitor frequently enough throughout the day to capture postprandial glucose excursions. Participants may need more education regarding the relationship between monitoring blood glucose, especially postprandially, and carbohydrate intake to see patterns in dietary intake and the postprandial glucose response. More research is needed to determine the relationships perceived by adults with diabetes between blood glucose self-monitoring and dietary intake to better refine the instrument used in this study.

Individuals who perceive themselves to be highly efficacious expect favourable outcomes. Many of the outcome expectations are related to the same behaviour on the self-efficacy instrument. For example, the efficacy belief 'I can control the amount of food I eat by measuring my portions of food' is related to the expectation 'The serving size of the foods I eat affects my blood glucose after a meal'. People decide on which course of action to pursue and how long to pursue it based on the adequacy of their performance ${ }^{34}$. Individuals avoid behaviours that they believe they cannot perform successfully and that they expect will lead to negative outcomes, but they actively pursue behaviours that they believe they can perform successfully and hold promise of valued rewards ${ }^{34}$. The self-efficacy instrument includes efficacy beliefs for the behaviours needed to adopt a lower GL diet (i.e. control the quantity of carbohydrate consumed and choose lower GI foods in various settings) and monitor the glycaemic response obtained. The items comprising self-regulation efficacy were significantly related to each of the constructs on the outcome expectations instrument. The items comprising GI efficacy were significantly correlated to glycaemic control expectations. These relationships suggest that individuals who feel more confident in their ability to regulate their dietary intake expect to overcome barriers to dietary change and impact glycaemic control. Further research is needed, however, to determine if education about how to adjust carbohydrate intake based on pre- and postprandial glucose excursions improves participants' efficacy for achieving glycaemic control.

A few limitations of this research should be noted. First, the instruments were administered among a primarily white, well-educated sample. The psychometric properties of the instruments among a culturally diverse sample or a sample of people with type 2 diabetes with limited literacy skills are not known. Secondly, the degree to which education improves participants' outcome expectations and self-efficacy for adopting a lower GL diet requires further research. Thirdly, the relationship between participants' expectations and self-efficacy for adopting a lower GL diet and dietary intake is not known. Whether improvements in these theoretical constructs results in a lower GL diet among people with diabetes requires further evaluation. Finally, controlled feeding studies in which participants have most of their meals provided to them demonstrate that a lower GI diet improves glycaemic control ${ }^{24}$. Whether the adoption of a lower GL diet improves glycaemic control among a freeliving sample of people with diabetes has not been adequately determined and requires further investigation.

\section{Conclusions}

The two instruments developed for this study adequately assess outcome expectations and self-efficacy for adopting a lower GL diet and monitoring the glycaemic response obtained. The outcome expectations instrument includes three homogeneous constructs regarding barrier, glycaemic control and family support expectations. The self-efficacy instrument includes three homogeneous constructs regarding GI, negative food selection and self-regulation efficacy. Each instrument can be used independently or in combination to assess areas requiring further education and training to adopt a lower GL diet. The instruments can be self-administered inexpensively in a relatively brief period of time. The instruments can be used to identify behaviours that may be perceived as difficult to change, situations in which there is an increased risk for relapse, or for programme evaluation. The effectiveness of a lower GL diet to improve glycaemic control among people with type 2 diabetes and the role of outcome expectations and/or self-efficacy to mediate this improvement require further research. However, based upon the results of this study, the instruments show promise as tools for increasing our understanding of the relationship between these theoretical constructs and health behaviours.

\section{Acknowledgements}

The College of Health and Human Development of The Pennsylvania State University provided funding for this study. The time and participation of study participants are deeply appreciated. C.K.M. and M.D.G. designed the study and carried out all aspects of data collection. F.L. assisted with the statistical analyses.

\section{References}

1 Harris ML. Diabetes in America: epidemiology and scope of the problem. Diabetes Care 1998; 21(Suppl. 3): C11-14.

2 Mokdad AH, Bowman BA, Ford ES, Vinicor F, Marks JS, Koplan JP. The continuing epidemics of obesity and diabetes in the United States. Journal of the American Medical Association 2001; 286: 1195-200.

3 Wild S, Roglic G, Green A, Sicree R, King H. Global prevalence of diabetes: estimates for the year 2000 and projections for 2030. Diabetes Care 2004; 27: 1047-53.

4 Ohkubo Y, Kishikawa H, Araki E, Miyata T, Isami S, Motoyoshi $\mathrm{S}$, et al. Intensive insulin therapy prevents the progression of diabetic microvascular complications in 
Japanese patients with non-insulin-dependent diabetes mellitus: a randomized prospective 6-year study. Diabetes Research and Clinical Practice 1995; 28: 103-17.

5 UK Prospective Diabetes Study (UKPDS) Group. Intensive blood-glucose control with sulphonylureas or insulin compared with conventional treatment and risk of complications in patients with type 2 diabetes (UKPDS 33). Lancet 1998; 352: 837-53.

6 American Diabetes Association. Evidence-based nutrition principles and recommendations for the treatment and prevention of diabetes and related complications. Diabetes Care 2002; 25(Suppl. 1): S50-60.

7 Jarvi AE, Karlstrom BE, Granfeldt YE. Improved glycemic control and lipid profile and normalized fibrinolytic activity on a low-glycemic index diet in type 2 diabetic patients. Diabetes Care 1999; 22: 10-8.

8 Sheard NF, Clark NG, Brand-Miller JC, Franz MJ, Pi-Sunyer FX, Mayer-Davis E, et al. Dietary carbohydrate (amount and type) in the prevention and management of diabetes: a statement by the American Diabetes Association. Diabetes Care 2004; 27: 2266-71.

9 Miller JCB. Importance of glycemic index in diabetes. American Journal of Clinical Nutrition 1994; 59(Suppl.): 747S-52S.

10 Ludwig DS. The glycemic index: physiological mechanisms relating to obesity, diabetes, and cardiovascular disease. Journal of the American Medical Association 2002; 287: 2414-23.

11 Hodge AM, English DR, O'Dea K, Giles GG. Glycemic index and dietary fiber and the risk of type 2 diabetes. Diabetes Care 2004; 27: 2701-6.

12 Salmeron J, Ascherio A, Rimm EB, Colditz GA, Spiegelman D, Jenkins DJ, et al. Dietary fiber, glycemic load, and risk of NIDDM in men. Diabetes Care 1997; 20: 545-50.

13 Salmeron J, Manson JE, Stampfer MJ, Colditz GA, Wing AL, Willett WC. Dietary fiber, glycemic load, and risk of noninsulin-dependent diabetes mellitus in women. Journal of the American Medical Association 1997; 277: 472-7.

14 Michaud DS, Fuchs CS, Liu S, Willett WC, Colditz GA, Giovannucci E. Dietary glycemic load, carbohydrate, sugar, and colorectal cancer risk in men and women. Cancer Epidemiology, Biomarkers \& Prevention 2005; 14: 138-43.

15 Franceschi S, Dal Maso L, Augustin L, Negri E, Parpinel M, Boyle P, et al. Dietary glycemic load and colorectal cancer risk. Annals of Oncology 2001; 12: 173-8.

16 Ma Y, Olendzki B, Chiriboga D, Hebert JR, Li Y, Li W, et al. Association between dietary carbohydrates and body weight. American Journal of Epidemiology 2005; 161: 359-67.

17 Jarvi AE, Karlstrom BE, Granfeldt YE, Bjorck IME, Vessby $\mathrm{BOH}$, Asp NGL. The influence of food structure on postprandial metabolism in patients with non-insulindependent diabetes mellitus. American Journal of Clinical Nutrition 1995; 61: 837-42.

18 Anderson JW, Randles KM, Kendall CWC, Jenkins DJA. Carbohydrate and fiber recommendations for individuals with diabetes: a quantitative assessment and meta-analysis of the evidence. Journal of the American College of Nutrition 2004; 23: 5-17.

19 Brand JC, Colagiuri S, Crossman S, Allen A, Roberts DCK, Truswell AS. Low-glycemic index foods improve long-term glycemic control in NIDDM. Diabetes Care 1991; 14: 95-101.

20 Buyken AE, Toeller M, Heitkamp G, Karamanos B, Rottiers R, Muggeo M, et al. Glycemic index in the diet of European outpatients with type 1 diabetes; relations to glycosylated hemoglobin and serum lipids. American Journal of Clinical Nutrition 2001; 73: 574-81.

21 Wolever TMS, Jenkins DJA, Vuksan V, Jenkins AL, Buckley GC, Wong GS. Beneficial effect of a low glycaemic index diet in type 2 diabetes. Diabetic Medicine 1992; 9: 451-8.

22 Ford ES, Liu S. Glycemic index and serum high-density lipoprotein cholesterol concentration among US adults. Archives of Internal Medicine 2001; 161: 572-6.
23 Jenkins DJA, Wolever TMS, Kalmusky J, Giudici S, Giordano C, Wong GS, et al. Low glycaemic index carbohydrate foods in the management of hyperlipidemia. American Journal of Clinical Nutrition 1985; 42: 604-17.

24 Brand-Miller J, Hayne S, Petocz P, Colagiuri S. Low-glycemic index diets in the management of diabetes: a meta-analysis of randomized controlled trials. Diabetes Care 2003; 26: 2261-7.

25 Trevino RP, Pugh JA, Hernandez AE, Menchaca VD, Ramirez RR, Mendoza M. Bienestar: a diabetes risk-factor prevention program. Journal of School Health 1998; 68: 62-7.

26 Kingery PM, Glasgow RE. Self-efficacy and outcome expectations in the self-regulation of non-insulin dependent diabetes mellitus. Health Education 1989; 20: 13-19.

27 Hurley CC, Shea CA. Self-efficacy: strategy for enhancing diabetes self-care. Diabetes Educator 1992; 18: 146-50.

28 Skelly AH, Marshall JR, Haughey BP, Davis PJ, Dunford RG. Self-efficacy and confidence in outcomes as determinants of self-care practices in inner-city African-American women with non-insulin-dependent diabetes. Diabetes Educator 1995; 21: 38-46.

29 Miller CK, Edwards L, Kissling G, Sanville L. Evaluation of a theory-based nutrition intervention for older adults with diabetes mellitus. Journal of the American Dietetic Association 2002; 102: 1069-74, 1079-81.

30 Bandura A. Social Foundations of Thought and Action: A Social Cognitive Theory. Englewood Cliffs, NJ: PrenticeHall, Inc., 1986.

31 Baranowski T, Perry CL, Parcel GS. How individuals, environments, and health behavior interact: social cognitive theory. In: Glanz K, Lewis FM, eds. Health Behavior and Health Education: Theory, Research, and Practice, 3rd ed. San Francisco, CA: Jossey-Bass, 2002; 165-84.

32 Davis MS, Miller CK. Educational needs regarding the glycemic index in diabetes management. Topics in Clinical Nutrition 2006; 21: 17-25.

33 Miller CK, Probart CK, Achterberg CL. Knowledge and misconceptions about the food label among women with non-insulin-dependent diabetes mellitus. Diabetes Educator 1997; 23: 425-32.

34 Bandura A. Self-efficacy: The Exercise of Control. New York, NY: WH Freeman and Company, 1997.

35 Pajares F, Hartley J, Valiante G. Response format in writing self-efficacy assessment: greater discrimination increases prediction. Measurement and Evaluation in Counseling and Development 2001; 33: 214-21.

36 Benson J. A redefinition of content validity. Educational and Psychological Measurement 1981; 41: 793-802.

37 Martuza VR. Applying Norm-referenced and Criterionreferenced Measurement in Education. Boston, MA: Allyn \& Bacon, Inc., 1977.

38 Cattell RB. The scree test for the number of factors. Multivariate Behavior Research 1966; 27: 509-40.

39 Lawrence FR, Hancock GR. Conditions affecting integrity of a factor solution under varying degrees of overextraction. Educational and Psychological Measurement 1999; 59: 549-79.

40 Hancock GR. Effect size, power, and sample size determination for structured means modeling and mimic approaches to between-groups hypothesis testing of means on a single latent construct. Psychometrika 2001; 66: 373-88.

41 van der Bijl J, van Poelgeest-Eeltink A, Shortridge-Baggett L. The psychometric properties of the diabetes and management self-efficacy scale for patients with type 2 diabetes mellitus. Journal of Advanced Nursing 1999; 30: 352-9.

42 Hancock GR, Mueller RO. Rethinking construct reliability within latent variable systems. In: Cudeck R, Toit SD, Sorbom D, eds. Structural Equation Modeling: Present and Future. Lincolnwood, IL: Scientific Software, International, 2001; 195-216. 